\title{
Radiological Evaluation of the effects of varied doses of Celecoxib on fracture healing in dogs
}

\author{
Edwin Aihanuwa Uwagie-Ero and Rapheal Chukwujekwu Kene \\ University of Nigeria, Nsukka, Nigeria \\ * Corresponding author email : eddyero@yahoo.com
}

\begin{abstract}
To determine if Cyclooxygenase -2 (COX-2) functions in fracture healing, 10 dogs were treated with COX-2-selective nonsteroidal anti-inflammatory drugs (Celecoxib) to reduce and stop COX-2-dependent prostaglandin production. Radiographic testing evaluation determined that fracture healing was not affected in dogs treated with a low dose of COX-2-selective NSAIDs (celecoxib) and delayed union was observed in dogs treated with a high dose of COX-2selective NSAIDs (celecoxib). Celecoxib dose of $5 \mathrm{mg} / \mathrm{kg} /$ day did not affect fracture callus formed in the study group and did not cause a significant increase in the proportion of delayed unions, however, at a dose of $10 \mathrm{mg} / \mathrm{kg} / \mathrm{day}$ it reduced the rate of fracture callus formation and significantly increased the proportion of delayed unions for dogs in the group.

Key Words: Analgesia, Celecoxib, Cyclooxygenase, dog, Fracture healing.
\end{abstract}

\section{I ntroduction}

Considerable evidence has shown that conventional nonspecific, non-steroidal, anti-inflammatory drugs, such as ibuprofen, ketoprofen, ketorolac and indomethacin, have an inhibitory effect on fracturehealing as well as other forms of postoperative bone repair (Allen et al, 1980; Huo et al, 1991). In recent studies, comparing nonselective, non-steroidal, antiinflammatory drugs and COX-2-selective drugs in rats, impaired fracture-healing was observed, with a greater effect seen in association with the COX-2selective drugs (Altman et al, 1995). Recent studies on the use of selective prostaglandin-receptor agonists have shown that stimulation of the EP2 or EP4 prostaglandin E2 (PGE2) receptor specifically promotes bone-healing (Gerstenfeld et al, 2003). Prostaglandins play an important role in the regulation of osteoblast and osteoclast functions, and inhibition of Prostaglandin production retards bone formation. Therefore, non steroidal, anti-inflammatory drugs (NSAIDs) could be expected to have significant consequences in divergent clinical situations where bone formation or remodelling is a contributory factor. NSAIDs are used clinically to prevent ectopic bone formation also known a heterotrophic ossification (e.g. after total hip arthroplasty or trauma). The efficacy of NSAIDs in the avoidance of heterotrophic ossification has been documented in controlled clinical trials, but the inherent risk on bone fracture healing processes and loosening of implants need further studies (Goodman et al, 2003).

\section{Material and Methods}

10 mongrel dogs (12-18 months old) were used for the clinical study. All anaesthetic and surgical procedures were performed in conformity with the existing University of Nigeria, Nsukka, Faculty of Veterinary Medicine ethics on animal handling and research.

Anaesthesia: Animals were premedicated with Atropine (Atrocare, Animal Care, UK) $50 \mathrm{mcg} / \mathrm{kg}$ IM and Xylazine (Xylacare 2\%, Animalcare, UK) $1 \mathrm{mg} / \mathrm{kg}$ IM. Anaesthesia was induced with Ketamine (Vetalar-V, Pfizer, Germany) $10 \mathrm{mg} / \mathrm{kg} \mathrm{IM}$ and maintained with Ketamine (Vetalar-V, Pfizer, UK) $10 \mathrm{mg} / \mathrm{kg}$ IM.

Surgery: The femoral diaphysis was exposed by incision and blunt dissection. Using a bone saw, a simple transverse fracture was created at the mid shaft of the femoral diaphysis. Spatial re-alignment of the bone was achieved by insertion of a $4.5 \mathrm{~mm}$ single armed IM pin. A post surgical radiograph was immediately taken to assess fixation system and confirm alignment of the fractured segment.

Post-operative Management and Care: Analgesics and Antimicrobials: Dogs in Group 1 were treated with Celecoxib (Celebrex®,Pfizer, Germany) $5 \mathrm{mg} / \mathrm{kg}$ P.O daily from day 0-14 and Enrofloxacin (Conflox ${ }^{\circledR}$ Animal Care, Nigeria) 10mg/kg IM; b.i.d from day 0-5. Dogs in group 2 were treated with Celecoxib (Celebrex®,Pfizer, Germany) $10 \mathrm{mg} / \mathrm{kg}$ P.O daily from day 0-14 and Enrofloxacin (Conflox ${ }^{\circledR}$ 
Animal Care, Nigeria) 10mg/kg IM; b.i.d from day 0-5. Radiography: Sequential radiographs were taken to evaluate fracture healing at weeks $2,4,6$ and 8 respectively. Development of periosteal callus indicated that indirect bone formation is occurring. Filling of stable fracture lines with bone indicated direct fracture healing.

\section{Results}

Radiology: Radiographs of animals in group 1; that received $5 \mathrm{mg} / \mathrm{kg}$ celecoxib showed distinct line of facture and periosteal bridging callus formation at week 2 . This was progressive at week 4 with cortical bridging calluses. By week 6 the fractures in animals in this group had radiographic evidence of union with progressive healing observed at week 8 there was clear evidence of bridging in the fractures in animals in this group. At week 2 the radiographs from animals in group 2; that received $10 \mathrm{mg} / \mathrm{kg}$ celecoxib showed distinct lines of fracture with no periosteal callus formation. At week 4, this group showed minimal periosteal callus formation in 4 dogsand yet no significant callus was formed in the last animal. At week 6 the callus formed was not bridging. At week 8; there was slight radiographic evidence of bridging.

\section{Discussion}

The results of this study show that Celecoxib at a dose of $5 \mathrm{mg} / \mathrm{kg}$ daily enhanced healing of stable transverse femoral fractures created and fixed with intramedullary pins, but at a dose of $10 \mathrm{mg} / \mathrm{kg}$ daily it retarded fracture healing.

This observation is supported by report that inhibition of cyclooxygenase-2 enzyme impairs fracture healing and that the effects are dependent on the dose (Gerstenfeld, et al, 2007). In animal studies in which a nonselective, non-steroidal, antiinflammatory drug was compared with a COX-2 selective drug in terms of the inhibitory effects on fracture-healing, impaired fracture-healing was shown to be greater when the COX-2 selective drug was used (Simon et al, 2002). The study showed that at low dose celecoxib did not inhibit the rate of callus formation and did not inhibit fracture healing but at high dose, there was delay in callus formation up to four weeks after fixation of the fracture and there was a significantly high rate of delayed union in the group. Finally, it is suggested that, use of celecoxib and other COX-2 selective inhibitors in fracture treatment should be done with caution, and at the lowest effective dose for pain relief bearing in mind the benefits of pain relief and inhibition of ectopic bone formation on one hand and the risk of non union and retarded union on the other hand.

\section{References}

1. Allen HL, Wase A, Bear WT. (1980) Indomethacin and aspirin:effect of nonsteroidal anti-inflammatory agents on the rate of fracture repair in the rat. Acta Orthop Scand.; 51:595-600.

2. Altman RD, Latta LL, Keer R, Renfree K, Hornicek FJ, Banovac K. (1995) Effect of nonsteroidal anti-inflammatory drugs on fracture healing: a laboratory study in rats. J Orthop Trauma.; 9:392-400.

3. Gerstenfeld LC, Cho TJ, Kon T, Aizawa T, Tsay A, Fitch J, Barnes GL, Graves DT, Einhorn TA.(2003) Impaired fracture healing in the absence of TNF-alpha signaling: the role of TNF-alpha in endochondral cartilage resorption. $J$ Bone Miner Res.; 18:1584-92.

4. Goodman SB, Ma T, Genovese M, Lane Smith R. (2003) COX-2 selective inhibitors and bone. Int J Immunopathol Pharmacol.;16: 201 -5.

5. Huo MH, et. al. (1991) The influence of ibuprofen on fracture repair: biomechanical, biochemical, histologic, and histomorphometric parameters in rats. J Orthop Res.;9:883 906. Simon AM, Manigrasso MB, O'Connor JP. (2002) Cyclo-oxygenase 2 function is essential for bone fracture healing. J Bone Miner Res; 17:963 -76. 